\title{
Prestige in social dilemmas: A network analytic approach to cooperation among Bogotá's art organizations
}

\author{
Annatina Aerne \\ University of St. Gallen, Müller-Friedberg-Strasse 8, 9000, St.Gallen, Switzerland
}

\section{A R T I C L E I N F O}

\section{Keywords:}

Cooperation

Social dilemma

Prisoner's dilemma

Collective action

Public goods

Prestige

Reputation

Network analysis

Temporal exponential random graph models

Organizations

Inter-organizational cooperation

Art

Art scene

Art organizations

Galleries

Latin America

Colombia

Bogotá

\begin{abstract}
A B S T R A C T
What brings about cooperation in social dilemmas? The literature has proposed motivational and strategic solutions to social dilemmas. In motivational solutions, actors cooperate because they care about fairness. In strategic solutions actors cooperate because their chances to exploit others are reduced. This paper argues that actors also cooperate in order to gain prestige. The effect of prestige on cooperation is examined relying on a unique set of network and covariate data on art organizations (museums, independent art spaces, galleries and art foundations) in Bogotá, the capital of Colombia. Bogotá is a not a very likely environment for cooperation, since distrust is still widespread after a long civil war. The temporal exponential random graph models predict dyadic cooperation (i.e., between two actors) based on past and present cooperation in the network as well as of the organizations' characteristics. The analysis thus controls for the effect of actors' past and present interaction on the present cooperation dilemma. The paper shows that prestige affects cooperation in social dilemmas independent of past and present interactions.
\end{abstract}

\section{Introduction}

A social dilemma designates a situation in which individual and collective rationality diverge. Actors, or organizations, are said to cooperate, when they decide for the greater good rather than follow their self-interest, without being forced to do so by a higher authority (Elster, 1989: 40). The literature on social dilemma has proposed motivational and strategic solutions (Kollock, 1998: 192). Motivational solutions are based on the fact that actors care about fairness and reciprocity. Actors, under certain conditions, choose to contribute to the greater good rather than pursue their own interests (Fehr and Schmidt, 1999: 837; Fehr and Fischbacher, 2004: 187; Winter et al., 2012: 929; Irwin and Simpson, 2013: 1069).

Strategic solutions in contrast analyze how rational behavior might nonetheless maximize collective benefits, by addressing opportunities to exploit others. Chances to exploit others are reduced by warranted information on actors' inclination to cooperate. This information travels across time and social space and allows actors to avoid uncooperative others. Such information on actors' inclination to cooperate is referred to as reputation (Axelrod, 1984; Granovetter, 1985; Raub and Weesie, 1990; Macy and Skvoretz, 1998; Starkey et al., 2000; Tomochi, 2004; Dijkstra and van Assen, 2013).

This paper explores a third solution to cooperation, namely prestige. Prestige refers to the fact that in society some actors defer, or yield, to others. Deference is that component of activity which functions as a symbolic means by which appreciation is regularly conveyed to a recipient (Goffman, 1956: 477; Freeland and Hoey, 2018). Such appreciation can only be received from others. Yet, gaining prestige is in the self-interest of actors. Gaining prestige is thus a motive that presupposes no pro-social orientation, but still requires relations with others. In cooperation dilemma, less prestigious actors may be induced to cooperate with more prestigious partners in order to gain prestige

E-mail address: annatina.aerne@unisg.ch. 
themselves. More prestigious actors on the other hand may wish to avoid less prestigious actors. The paper explores under what conditions prestige gains may motivate actors to cooperate in social dilemma.

This paper examines cooperation between art organizations ${ }^{i}$ (museums, galleries, independent art spaces, and art foundations) in Bogotá in the period from 2011 to 2015 . The four forms of cooperation analyzed in this paper involve multiple actors that need to undertake individual efforts to achieve a collective benefit. Such multi-actor social dilemmas are commonly referred to as collective action problems. In the case analyzed here, art organizations share individually generated audiences or circulate individually curated content across different art organizations. Four forms of cooperation are thus analyzed: (1) circulation of visitors (i.e. noche de galerías); (2) participation in joint events (i.e., multiple organizations invite their publics to an art fair); (3) organizing joint events (i.e., organizations plan their own biennial); and (4) circulation of content (i.e., an organization presents an artist represented by another organization or an exhibition previously shown at another organization). Organizations undertake individual efforts to reach a common goal, without being certain that others will also contribute to this goal.

The paper uses network analytic methods, and applies temporal exponential random graph models (tergms) to a unique dataset in order to examine cooperation in social dilemmas. The exponential graph models condition cooperation between two organizations on all other present and past instances of interaction in the network. By controlling for present and past relations, the models control for a socially transmitted reputation, and to some extent also for prestige which is constituted in relations. In addition, prestige is also captured by an exogeneous measure, the number of event committees in which art organizations are represented. Art events (e.g., biennials and art fairs) are highly competitive and admission is decided on by event committees. Representation in these committees means peer recognition as a legitimate gatekeeper. The empirical analysis shows that prestige affects cooperation in social dilemmas independent of organizations' present and past interactions.

Section 2 reviews the solutions to social dilemmas suggested by the literature and introduces prestige as an additional factor hitherto not analyzed in the context of social dilemmas. Section 3 presents different forms of cooperation in Bogotá's art scene and shows that art organizations need to overcome a social dilemma situation. Section 4 introduces a unique dataset on the cooperation network existing among Bogotá's art organizations. Section 5 shows how the variables are operationalized, while section 6 explains the exponential random graph models and the temporal version of it. Section 7 presents the empirical analysis. Section 8 concludes and discusses implications for future research.

\section{Prestige: between strategic and motivational solutions to social dilemmas}

The difficulty of achieving cooperation in social dilemma stems from two causes: fear to be exploited and desire to exploit others (Simpson, 2003). On the one hand, actors fear that their cooperation will not be reciprocated and they will hence be exploited. On the other hand, actors hope that their counterpart will cooperate, thus enabling them to take advantage. Both, fear and desire to exploit hinders

\footnotetext{
${ }^{\text {i }}$ Four different kinds of organizations are included in this study: museums, independent art spaces, galleries and art foundations. The delineating criterion that links these organizations is that they exhibit art works and host exhibitions. They are distinct from one another with respect to profit-orientation, and source of finance. The paper analyses four forms of sharing content or audience: circulating visitors, organizing a joint event, participation in joint events and the circulation of artworks. These forms of cooperation involve either gathering smaller, individually generated audiences in one place or circulating individually curated content across different art organizations.
}

cooperation. Kollock (1998: 192) distinguished motivational from strategic solutions to achieve cooperation. ${ }^{\text {ii }}$ In motivational solutions, actors care about fairness and reciprocity, addressing actors' desire to exploit others. Strategic solutions, on the other hand, limit actors' chances of exploiting others. Prestige involves elements of both motivational and strategic solutions to achieving cooperation in social dilemmas.

Motivational factors helping to overcome social dilemmas take into account that actors care about fairness and reciprocity. Thus, motivational solutions refer to fairness norms. These make actors contribute to the greater good rather than pursue their own interests. Fehr and Fischbacher (Fehr and Fischbacher, 2004: 187) emphasized the importance of norms of fairness and reciprocity. They reported that actors, desiring justice, invest individual resources to sanction non-cooperators. Fairness considerations are hence important in overcoming prisoners' dilemmas. In ultimatum games, equity norms also motivate individual cooperation (Fehr and Schmidt, 1999: 837). While norms may foster cooperation, they may also entail conflict: Either when individuals do not comply with generally accepted norms (cheat) or when they don't agree on the same norms (Winter et al., 2012: 929). In public goods dilemmas, descriptive norms (i.e., compliance with one's peer group) also motivate cooperation (Irwin and Simpson, 2013: 1069).

So-called strategic solutions show how rational behavior might nonetheless maximize collective benefits, predominantly by addressing opportunities for exploiting others. Ascertained information on actors' inclination to cooperate that travels across time and social space is particularly relevant in these solutions. This warranted information on actors' inclination to cooperate is referred to as reputation. It allows potential partners to only cooperate with compliant counterparts. Organizations with a reputation for not cooperating are not selected as cooperation partners. A reputation may be built by repeated interactions with the same partners (Gulati and Gargiulo, 2000: 34). Axelrod demonstrated that time is crucial in cooperation (1984: 20). He suggested that cooperation evolves if individuals can engage in repeated interaction, despite their self-interest. This dynamic is also reflected by the tendency of organizations to maintain their partnerships from previous successful collaborations (Starkey et al., 2000: 299). Apart from past interactions, a social context may provide warranted information on actor behavior. Granovetter (1985) posited that interactions never occur in a social vacuum. For instance, actors are more likely to interact within their neighborhood (Macy and Skvoretz, 1998: 639). Given that interactions are socially embedded, actors also rely on

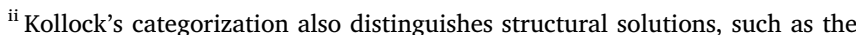
introduction of higher authorities that administer sanctions. In structural solutions, cooperation presupposes some sort of cohesion among the actors, or even an intermediate instance that coordinates. This is not always given and certainly not the case in the situation analyzed here. Although structural solutions are thus not as relevant to this analysis, I briefly outline the main findings of this strand of literature. Ostrom highlights the importance of graduated sanctions and monitoring in order to maintain cooperation (2000: 150). Sanctions are also emphasized by Sell and Wilson (1999) in a gametheoretic analysis that details how to overcome public goods dilemmas. Related to these solutions are analyses of collective action that also highlight the importance of certain structural characteristics, such as the presence of an authority. Olson (1965), for instance, studied how businesses overcome cooperation dilemmas, and how they cooperate to represent their interests in political processes. In the absence of coercive measures, employer associations usually provide specific private goods, or inducements, that motivate businesses to make the effort to join the association (Olson, 1965: 133). Culpepper (2000: 229) analyzed what motivates organizations to invest in employee education. Also important are central organizations, which convince the potentially most cooperative actors to make such investments. Similarly, Marwell et al. (1988: 503) employed a network analytic approach to analyze how different network structures influence group performance with regard to the provision of collective action. They showed that collective action is more easily achieved in groups with centralized structures.
} 
their trusted partner's experience with a third party when taking cooperation decisions (Raub and Weesie, 1990: 631). Combining network analysis with game theoretic models, Tomochi finds that the degree of cooperation depends on the share of connections in the network that are randomized (2004: 320). Cooperation is also sensitive to whether actors know how central their counterparts are in the respective network (Dijkstra and van Assen, 2013: 580). Moreover, cooperation depends largely on the investments necessary to maintain the network that transmits information, and the gains to be had from cooperation (Raub et al., 2013: 728). Thus, social relations are important in that they indicate an actor's cooperativeness. An actor's reputation to cooperate travels in time (repeated interaction) and in space (embeddedness). Such a reputation provides decisive information and reassurance about interaction habits. They serve to limit the risk of exploitation.

However, social relations may not only affect cooperation by transmitting a reputation. Social relations are also the basis of prestige. Prestige is constituted in relations and prestige gains may motivate actors to relate to others. Prestige commonly refers to the fact that some defer, or yield, to others (Freeland and Hoey, 2018). Deference refers to that component of activity which expresses appreciation to a recipient (Goffman, 1956: 477). Deference may take on two forms (Goffman, 1956: 486). First, it may take the form of avoidance, i.e. when a subordinate does not enquire after relatives of a superior and does not seek to be associated with lower-standing counterparts either. Second, deference may be presentational as in salutations, invitations, compliments, and minor services. In this latter form, less prestigious actors gain prestige in relating to more prestigious actors. They compensate the more prestigious actor for their gain in prestige by doing them a small favor. Lazega and Pattison in their analysis of cooperation in a law firm analyze how prestige-seeking may motivate lawyers to altruistically consult other lawyers (1999: 70).

In a social dilemma, prestige may induce less prestigious actors to cooperate. Cooperation in social dilemma may become a more attractive strategy because organizations wish to associate themselves with prestigious counterparts. Prestige therefore occupies a middle position between strategic and motivational solutions. Like a motivational solution, it supposes that actors can be motivated to cooperate. But unlike motivations such as reciprocity and fairness, prestige presupposes no pro-social orientation. Similar to strategic solutions, it realigns individual interests and collective benefits. Prestige in a way serves as a resource that enables prestigious actors to purchase cooperation from less prestigious actors. The relation between cooperation and prestige may be positive or negative: Organizations may cooperate in order to associate themselves with highly recognized others, meaning that highly recognized organizations may be more frequently involved in cooperation. However, prestigious organizations may also refuse cooperation, particularly with less recognized cooperation partners.

\section{Case: cooperation among art organizations in Bogotá}

The paper studies cooperation among art organizations in Bogotá. I thus make two decisions: one on the geographic area, and one on the type of organizations I analyze. The context of Bogotá is difficult for cooperation. However, art organizations are more likely to be driven by considerations of prestige, than other types of organizations. Artworks' quality cannot be measured objectively. Rather, the recognition depends on the confirmation of experts, institutions and networks assuring the prestige of these artworks . In this sense, choosing art organizations is a most likely case for observing the impact of prestige on cooperation. Since this article is a theory-building exercise, with prestige as main innovation, such a likely case is an appropriate set-up.

Bogotá's art sector is an unlikely case for studying cooperation. It is a post-conflict context and a luxury market in a developing economy. Thus, there is little demand, fierce competition, and low levels of cooperation. While the last ten years have brought political stabilization and some economic progress, the demand for luxury goods such as art remains relatively low in Colombia. There is only a handful of domestic collectors, and only one museum in Bogotá purchases artworks for its collection. Lacking funds means that the other museums rely on artists donating works. International demand for art has long been absent because Colombia was an unattractive destination for affluent art collectors. Local art organizations must therefore survive on scarce resources. Accordingly, competition for these few collectors and international visitors is strong. Achieving cooperation in such highly competitive environments is difficult (Bowles et al., 2003).

The four forms of cooperation involve multiple organizations, whose individual efforts result in a collectively desirable outcome (larger art audiences). As the four forms of cooperation involve multiple actors, they are best described as collective action problems. Organizations share individually generated audiences or circulate independently curated content across different art organizations: (1) circulation of visitors (i.e. noche de galerías); (2) participation in joint events (i.e., multiple organizations invite their publics to an art fair); (3) organizing joint events (i.e., organizations plan their own biennial); and (4) circulation of content (i.e., an organization presents an artist represented by another organization or an exhibition previously shown at another organization). Organizations thus invest individual resources to achieve a collective benefit, without being sure that the others will also contribute.

Cooperation in collective action problems can be broken down into different two-actor dilemmas, depending on the payoffs and on the costs incurred by individual actors. Collective action can thus be characterized as prisoner's dilemma, assurance games, and chicken games (Heckathorn, 1996: 257). Achieving cooperation in these three types of dilemma is not equally easy. Characteristic of collective action resulting in a prisoner's dilemma (which is particularly hard to overcome) is that the collective good must be more valuable than its production cost. But to constitute a prisoner's dilemma, its value cannot be more than double the production cost (Heckathorn, 1996: 258). It is plausible that the value of four forms of cooperation exceeds the costs (or else the organizations would hardly undertake such efforts). Based on the information of 36 expert interviews, I also know that the payoff for any particular organization in these forms of cooperation is lower than double the efforts. Participation in art fair for instance is very costly, due to the fees for a booth and shipping and insurance costs. Organizations are glad to break even in these art fairs. Benefits from these forms of cooperation are therefore very unlikely to exceed the double of the individual efforts. Thus, although the payoff structure of the particular forms of cooperation are unknown, it is likely that these collective action problems may be broken down into prisoner's dilemmas.

The difficulty to align individual incentives and collective benefits also becomes evident when cooperation fails to materialize. In the noche de galerías (Night of the Galleries), the participating galleries invite their customers to a guided walk visiting multiple galleries. Each individual gallery has an incentive not to invite its customer base but to receive the customers of other galleries. Collectively, it makes sense to coordinate individual efforts, since a joint event gets more attention and reaches customers that have not been interested in art so far. Cooperation in this format started in 2011 in the north of Bogotá. It worked well, as long as it took place only in this neighborhood. Over time, the circle expanded south to the new gallery sector San Felipe. Subsequently, cooperation broke down, because visitors preferred San Felipe's quickly growing gallery sector to the galleries in the north. The latter stopped contributing to the noche, while those in San Felipe launched their own event. As the example shows, balancing individual contributions and the benefits of cooperation is difficult.

The creation of prestige through association is particularly important in the art sector, where objective measurements of quality are not available. Art experience is ambiguous, meaning that neither the quality nor the value of art can be verified objectively, leaving both open to discussion. Art organizations connect with other (prestigious) organizations to create a supportive base for their selected artists and 
artworks. The success or acceptance of an artwork depends on organizations and networks affirming its status. Previous empirical research has analyzed the importance of prestige dynamics in artistic networks (Giuffre, 1999: 827; Nooy 2002: 152; van Dijk, 1999; Braden, 2009). Giuffre (1999) found that artists' careers depend on their representation in galleries over time. In the literary field, de Nooy (2002) analyzed how the artistic prestige of authors and literary journals build on one another. Art organizations' cooperation may thus be influenced by considerations of prestige to a larger extent, than other organizations. The article takes this into account by analyzing four forms of cooperation that are not all equally likely to be affected by prestige. More visible forms of cooperation, such as participation in art events or organization of art events together, are likely to be more sensitive to prestige effects. Differentiating the forms of cooperation allows analyzing to what extent prestige is context-specific to certain forms of cooperation.

\section{Data}

The original data for examining the role of prestige in cooperation comes from a survey that asked Bogotá's art organizations about their cooperation and characteristics retrospectively from 2011-2015. The survey collected data on 91 organizations.

The data included information on organizational interconnections. This allowed controlling for an organizations' reputation regarding cooperativeness and partly also prestige as transmitted through the network. The ergm models [see Section 6] predict two-actor cooperation based on (1) all other instances of cooperation in the network (endogenous variables) and (2) organizational characteristics (exogenous). Endogenous variables for instance control for an organization's tendency to connect with a friend's friend rather than with a complete stranger. They thus enable capturing an organization's reputation, understood as warranted information on cooperative behavior as indicated by one's past and present connections, and also, prestige as constituted in social relations. In addition, prestige is captured by an exogenous variable (art committee membership).

The survey was sent out to all of Bogotá's 128 art organizations active in 2015. The list of organizations was obtained from Arteria, an art magazine published annually together with the local Chamber of Commerce, the Directorio Bogotá Arte Circuito (Peñaranda et al., 2015). Arteria oversees the art scene in Bogotá well enough to compile a complete list of all art organizations. Although the questionnaire allowed respondents to indicate additional contacts, none were mentioned.

Every data collection approach has its limits and missing observations can hardly be avoided if one collects data relying on a survey. In a context such as Bogotá, cooperation is difficult and therefore worthwhile studying, but data gathering also tends to be more complicated. The missing observations were dropped from the datasets. To the author's knowledge, there is no established threshold in the literature as to what percentage of missing observations invalidates inference in network analysis. In contrast to most other analyses, the list by Arteria specifies the number and allows identifying the missing organizations. Such complete lists are rarely available in artistic circuits. It is often difficult to even know precisely the total number of active organizations, or artists in an art scene. Giuffre's seminal analysis on artists' networks analyses a sample of 159 contemporary photographers that received a grant from the National Endowment for the Arts, or had a solo show in a gallery in New York (Giuffre, 1999: 821). Her study had to leave open the question, how large this sample is in comparison to the total population of contemporary photographers. The list used in this study, in contrast, is comprehensive.

The list by Arteria also allows checking whether missingness is random across subgroups (missing at random, MAR). The data provided by Arteria included locations and categories also for non-participating organizations. This enables analyzing the association between organizations included in the sample and their "location." It also allows examining their inclusion and the variable "category" for evidence on how exogenous variables relate to organizations being included or not. Testing the association with a Chi-Squared test of independence, the association between "missing" and "category" results in a p-value of 0.31 , with a Chi-Squared of 3.56 and $\mathrm{df}=3$. For the 2015 sample, the association between "missing" and "location" results in a p-value of 0.23 , with a Chi-Squared of 2.97 and $\mathrm{df}=2$. Both $\mathrm{p}$-values are above usual levels of alpha (.05), needed to reject the null-hypothesis of independence between the categorical variables. Moreover, the missing organizations are not particular in a way that could explain their missingnesss (missing not at random, MNAR). As the author also conducted 36 interviews with the directors of the leading organizations prior to the survey, the possibility that the non-responding organizations form an interconnected component can be excluded (see supplementary materials for the list of interviews). The missing organizations are smaller galleries and independent art spaces that are not very central in the art circuit on the one hand, and on the other hand foundations, and museums that are not primarily concerned with contemporary art.

Alternative approaches to gather data, such as document analysis would not have enabled collecting a more complete dataset, but would have introduced serious sample bias. Online communication concerns only the larger organizations and is not available with respect to all the forms of cooperation going on in the art circuit. Major art fairs may be announced, but the exchange of artworks goes unmentioned. Moreover, in this emerging art scene in Bogotá, art events are usually announced on short notice on social media platforms and can often be found online only for a limited period of time. Art events back in 2011 could not have been retrieved in this way. An even less promising approach to data collection would have been to rely on printed materials. Catalogues on expositions are very expensive even for major art organizations in Bogotá. Relying on published (printed or online) material would thus have led to a bias in the sample.

\section{Operationalization}

This section operationalizes cooperation as a dependent variable and prestige as a main factor of cooperation. It also presents controls for the other explanations potentially affecting cooperation, in particular strategic and motivational solutions. It also draws on the literature on inter-organizational cooperation to account for the fact that this paper analyzed organizations.

\subsection{Cooperation network}

The dependent variable is whether any two art organizations cooperated at any time during the period of investigation (2011-2015). The respondents indicated their contacts with any of the other 128 organizations during the previous five years. After selecting their cooperation partners, they were asked to indicate their forms of collaboration and when cooperation had occurred. The entries in these matrices are 0 or 1 . They represent whether or not the organizations in a particular row and in a particular column were cooperating with each other at a given time. As the respondents did not always agree about when they cooperated with whom, the matrices are not symmetrical. I refrained from symmetrizing the networks in order to avoid a loss of information. The models presented later do not differentiate incoming and outgoing ties. ${ }^{\text {iii }}$ Based on the organizations' characteristics and network measures, they predict connections between any two nodes (dyad).

\footnotetext{
iii I also estimated the directed versions of the models and found that the effect of prestige on the probability of incoming and outgoing ties did not diverge in direction or significance for four of the six models. The coefficients for prestige for incoming and outgoing ties diverged in the two forms of cooperation in which prestige is insignificant in the undirected model. The good fit of the undirected models furthermore suggests that the analysis adequately represents tie formation even while omitting this more differentiated analysis.
} 


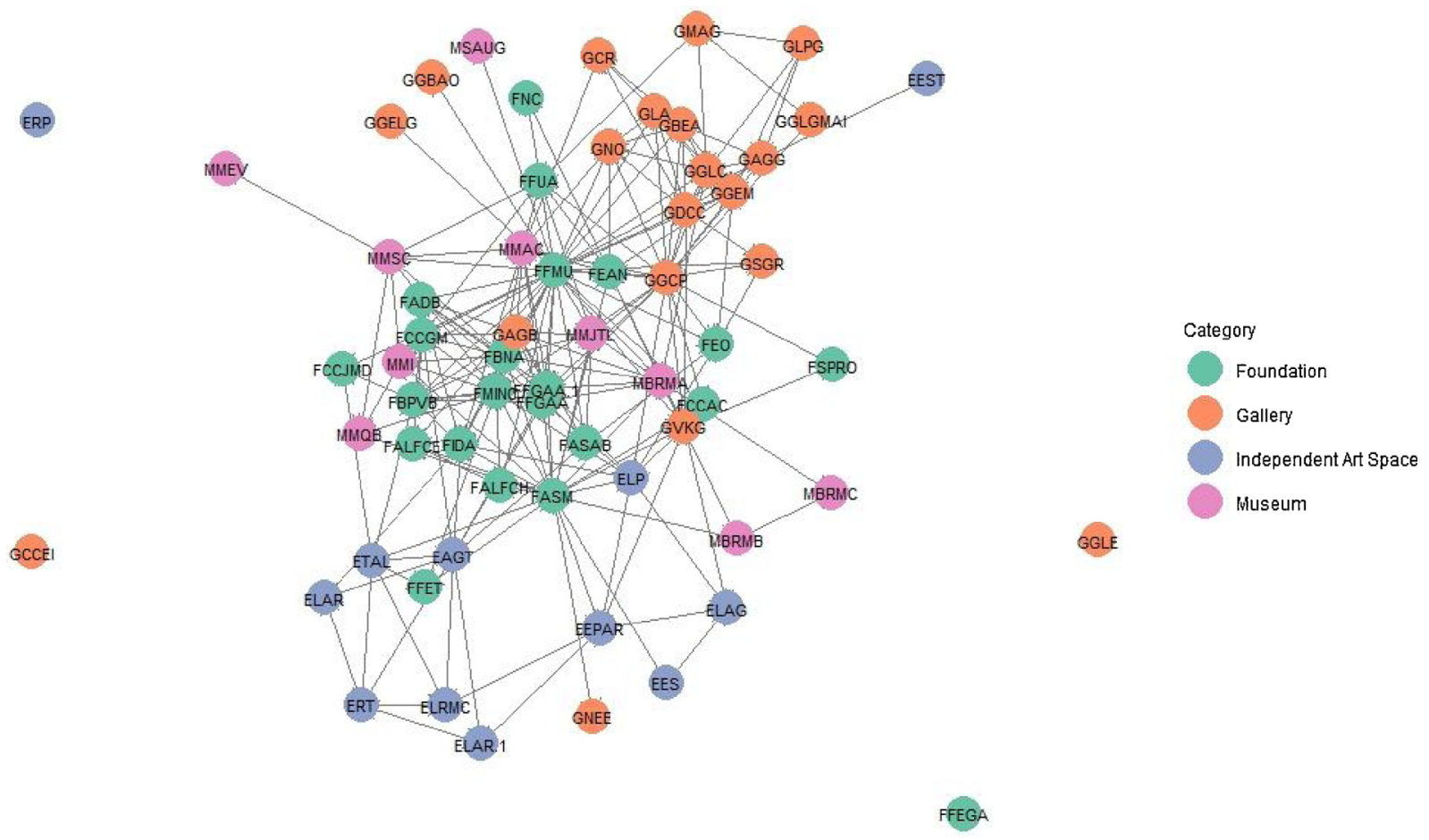

Fig. 1. Combined Art Network 2011 (64 organizations). Cutoff $=1$. Source: Own Data.

Below are exemplary visualizations of two of the combined networks for 2011 and 2015 (for the visualization of the networks in the other years see the supplementary materials). Combined means adding the four different adjacency matrices for the different forms of cooperation. This resulted in matrices with values from 0 to 4 for cooperation among any two organizations, depending on whether they had contact only through one form or through multiple forms of cooperation. The valued network was then dichotomized with a cut-off of one (see supplementary material for sensitivity analysis for different cut-offs). The networks were adjusted to only include organizations existing in the respective years. That left 64 organizations in 2011, 75 in 2012, 80 in 2013, 89 in 2014, and 93 in 2015.

Comparing the two network graphs (2011: Fig. 1; 2015: Fig. 2) reveals two tendencies. First, similar organizations tend to cooperate among themselves. Second, network density (i.e., the ratio between actually observed ties and the number of all possible ties) was higher in 2015 than in 2011. This may be due to the fact that respondents remember their cooperation patterns for 2015 better than for 2011. The temporal exponential random graph models will control for that tendency, as explained below. The densities for the 2012-2014 networks are comparable. The degree distributions are comparable across years. The 2015 network deviates insofar as more organizations exhibited an intermediate number of ties. No clear tendency regarding different centralization measures is evident either (see supplementary material for information on all the network statistics).

\subsection{Prestige}

Prestige is here represented by the number of committee memberships an organization is represented in by their director. Admission committees decide on acceptance to particular events in Bogotá (e.g., an art fair). Usually, admission is by application and evaluated by committees. Committee members are perceived to have enough expertise to evaluate the applications of peer organizations. Art organizations are associated with the prestige gained by their director in two ways. First, committee members are selected based on the standing of the organization they direct. They are not selected into these committees independently of their directing this particular art organization. Insofar, it is fair to say that they represent their organization in these event committees. Moreover, a directors' selection into the committee also reflects back and increases the art organizations' standing. The questionnaire asked whether the organization was presented in these committees, not whether the director (who might have changed organizations) was participating. Examining the 2011-2015 issues of Arteria established the following major events in Bogotá's art sector: artBo (2011-2015), La Otra (2011, 2012, 2013), Odeón (2011-2015), Sincronía (2012, 2014), Barcú $(2014,2015)$ and Premio Luis Caballero (2011, 2013, 2015). Counting the number of potential committee memberships resulted in maximally four committee memberships per year. The variable thus ranges from values of zero (i.e., no committee participation) to maximally four committee memberships. In 2015, the observed minimum of this variable was 0 , the maximum equaled 4 . The mean amounted to 0.15 , and the median was 0 . The standard deviation was 0.51 (see supplementary materials for descriptive statistics for all exogenous variables for all five years).

Also assessed was whether organizations cooperate across different levels of prestige. The differences in committee membership and their effect on connection likelihood were modeled with an absolute difference term. A positive coefficient on the absolute difference term indicates a tendency to cooperate across different levels of prestige. While highly recognized organizations might be expected to only cooperate with counterparts of similar standing, less recognized organizations strive to connect with more recognized organizations to gain prestige.

Prestige is inherently relational. Art organizations' gain their prestige in relation to other, recognized organizations and artists (Giuffre, 1999: 827; de Nooy, 2002: 152; van Dijk, 1999; Braden, 2009). As de Nooy describes for literary art scene, measuring prestige in artistic scenes may lead to an infinite regression: A's prestige depends on B's prestige, which may depend on C's prestige, which may depend on A's prestige and so forth (Nooy 2002: 150). The dependent variable (relations) is difficult to separate from the independent (prestige built through relations), and also from reputation which is transmitted in social relations. Luckily, the models presented here allow for controlling for existing connections within the same network, as well as for 


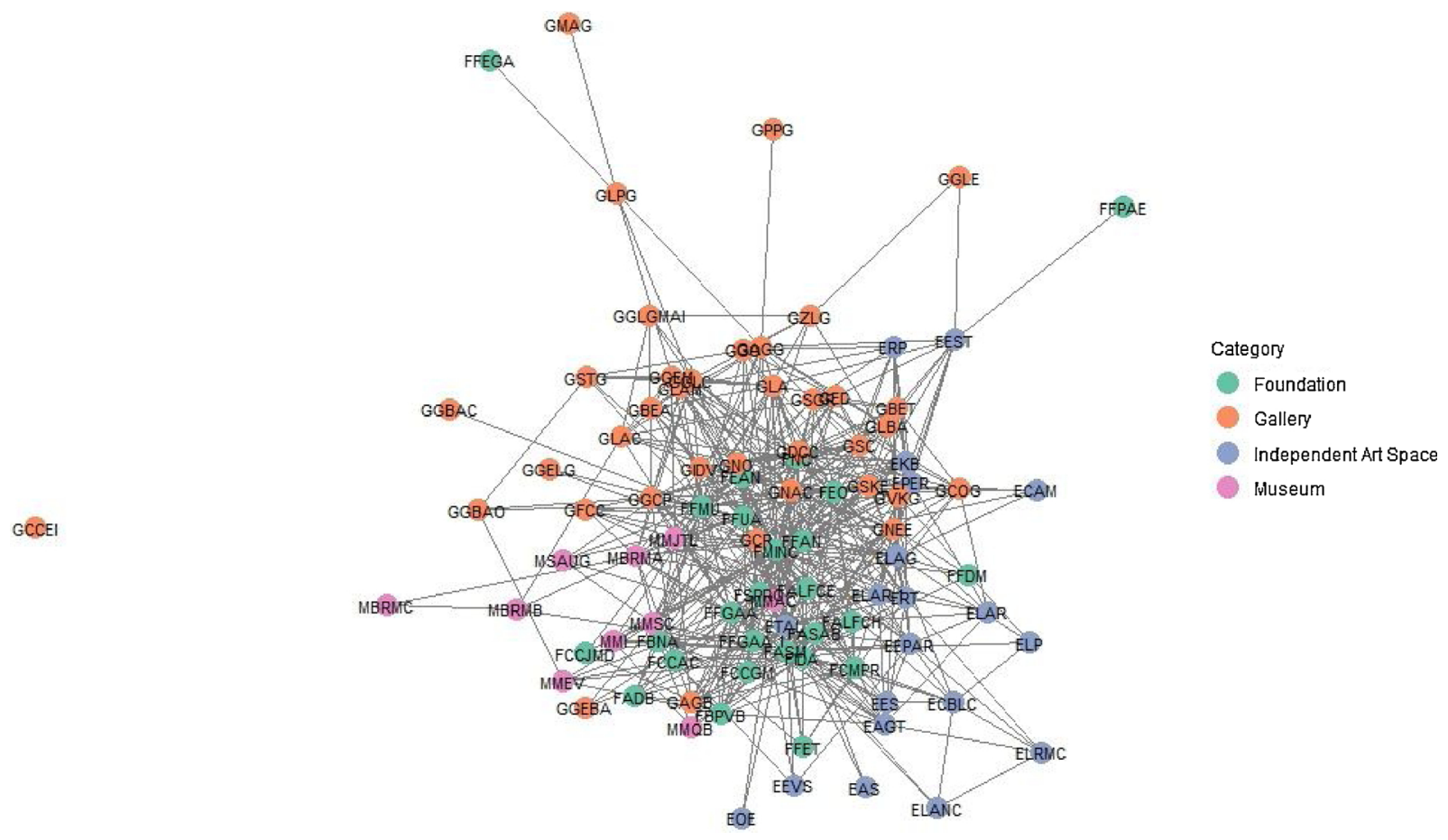

Fig. 2. Combined Art Network 2015 (93 organizations), Cutoff $=1$. Source: Own Data.

Dyad-wise shared partners

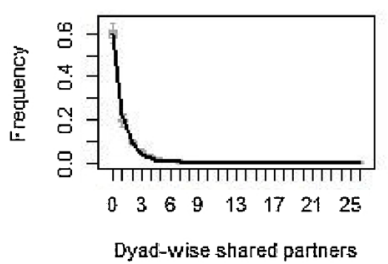

Indegree

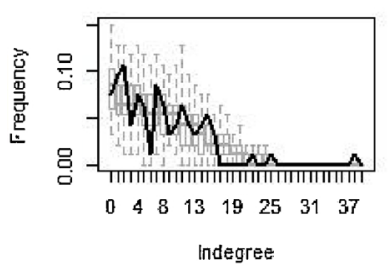

Modularity (walktrap)

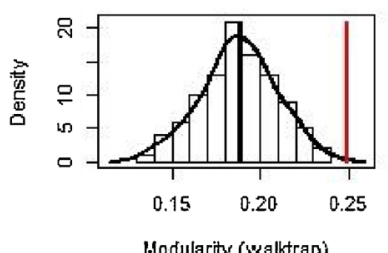

Edge-wise shared partners

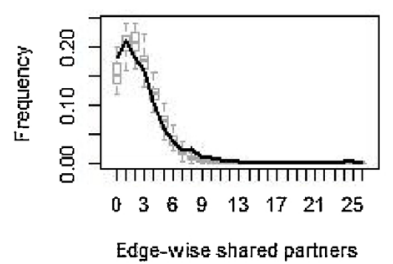

Geodesic distances

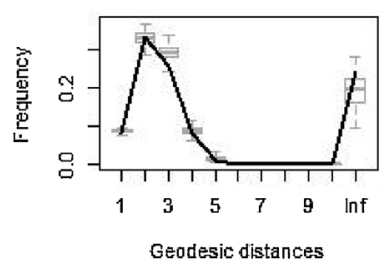

Degree
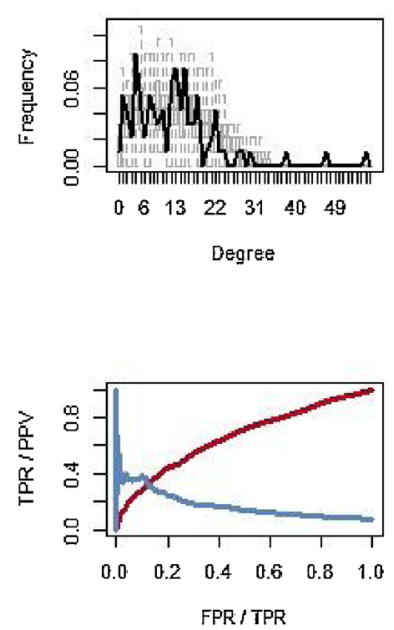

Fig. 3. Goodness of Fit Plot for the ergm on the Combined and Dichotomized Network for 2015. Source: Own Data.

past instances of cooperation. The models thus control for the prestige constituted and the reputation transmitted in relations. This makes sure that the effect of prestige measured as committee membership is accurate, and it actually makes it harder to find an effect. The measure applied here, (an art organization's representation in an event committee) captures the inherent relational nature of prestige, but at the same time is also measurable and observable. The operationalization chosen in this paper compares to other analyses on the role of prestige in cooperation in artistic circuits. Studies typically choose an observable measure, such as literary prizes, or mentionings in artistic journals to measure prestige and then relate the effect of prestige to the relations of the actors (Verboord, 2003: 265; Nooy 2002: 155; Giuffre, 1999: 821). 
Dyad-wise shared partners

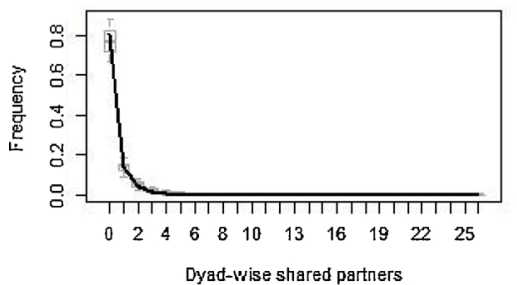

Indegree

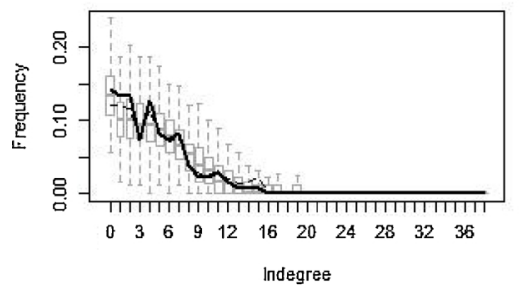

Modularity (walktrap)

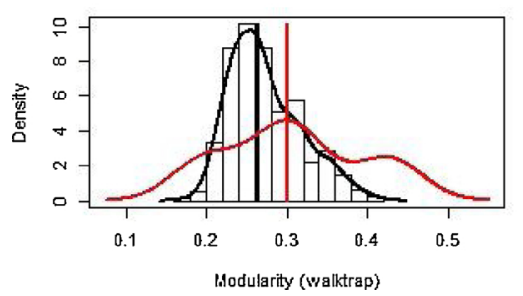

Edge-wise shared partners

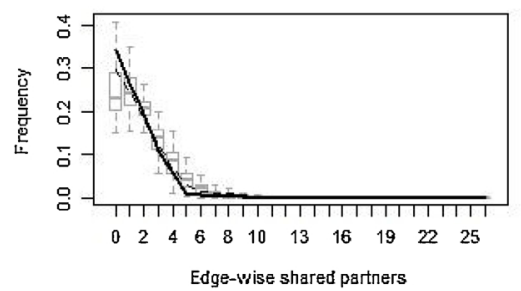

Geodesic distances

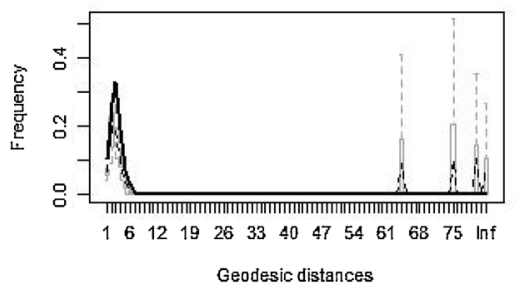

Degree
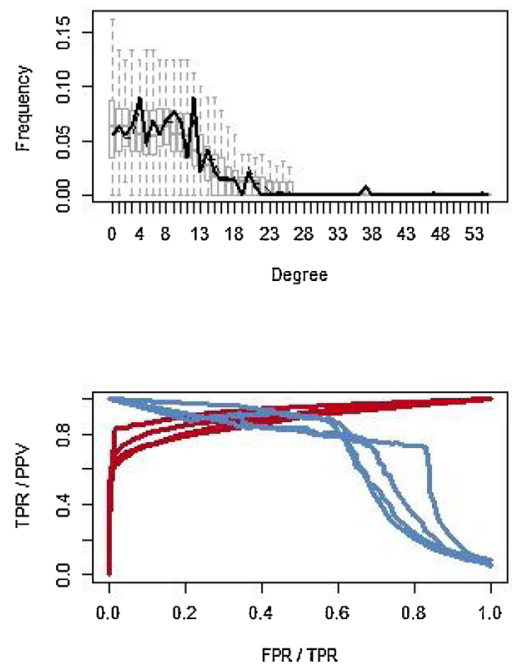

Fig. 4. Goodness of Fit Plot for the Temporal ergm for the Five Networks from 2011 to 2015 with a Memory Term of Type 'Stability'. Source: Own Data.

\subsection{Social embeddedness}

Social relations play a role in cooperation dilemma in two ways. As mentioned in the previous paragraph, social networks indicate prestige. Moreover, social networks transmit a reputation signaling one's inclination to play along. It is essential to control for existing interactions in order to assess the effect of the measure for prestige independently. The models presented here therefore control for existing connections within the same network, for past instances of cooperation.

In the models, interactions depend on already existing connections within the modeled network. For instance, actors are more likely to be friends with their friends' friends. One advantage of the exponential random graph models presented here is that such constellations are explicitly modeled. Thus, organizations' tendency to cooperate with other organizations is modeled based on all existing network connections. The models presented here include a measure for transitivity. Transitivity is usually modeled with an edge-wise shared partner term (GW-esp). Here, it is included as a geometrically weighted term, i.e., a rate of decay of alpha (here 1.2) applies to a higher number of shared partners. Dyad-wise shared partners were included as a measure of intransitivity (GW-dsp). I also controlled for cyclicality, including a four-cycle. Also included were measures controlling for preferential attachment of organizations, with a GW-idegree, which sums the number of nodes of each indegree. GW-odegree sums the number of nodes of each outdegree. This is used to model the tendency that nodes with more outgoing ties (higher outdegree) are more likely to form additional ties. Isolates is a term that adds one statistic to the model equal to the number of isolates in the network. Finally, the term mutual controls for reciprocity within a network.

Organizations' tendency to cooperate with the same organizations over time is also controlled for. The temporal ergm model for the entire five years includes a memory term of type stability. The statistic counts the number of dyads remaining stable between two time points regardless of connection (Leifeld et al., 2018). The term may be written as $\mathrm{h}_{\mathrm{s}}=\Sigma_{\mathrm{ij}} \mathrm{N}_{\mathrm{ij}}^{\mathrm{t}} \mathrm{N}_{\mathrm{ij}}^{\mathrm{t}-1}+\left(1-\mathrm{N}_{\mathrm{ij}}^{\mathrm{t}}\right)\left(1-\mathrm{N}_{\mathrm{ij}}^{\mathrm{t}-1}\right)$. The term equals one if $\mathrm{N}_{\mathrm{ij}}{ }^{\mathrm{t}}$ and $\mathrm{N}_{\mathrm{ij}}{ }^{\mathrm{t}-1}$ take on the same values, i.e. are connected or unconnected in both times. However, the term results in 0 when they assume different values (i.e. change from 0 to 1 or vice versa).

Connections or non-connections that are stable across years are thus captured by this term, and do not affect the other coefficients. This memory term controls for two tendencies: first, the potential bias of organizations to extrapolate their cooperation from 2015 back to earlier years; ${ }^{\text {iv }}$ second, instances of cooperation that have truly been stable over time. This means, the term controls for a reputation transmitted through interactions, as well as for prestige established in previous relations. Unfortunately, it is not possible to disentangle genuine instances of continued cooperation from those that were simply extrapolated.

\subsection{Control variables}

In addition to the existing connections in the modeled network, the models also include controls that have been found to influence cooperation in other studies.

\footnotetext{
${ }^{\text {iv }}$ Survey respondents answered questions referring back to their activities in 2011 to 2015. Retrospective data collection is not unproblematic, since respondents will not remember 2011 as well as 2015. They are likely to extrapolate their experience from 2015 to previous years. Analyzing policy networks, Ingold and Fischer (2014) encountered the same problem in datagathering and adjusted for it as follows: (1) gathering data on all members so that cooperation indicated by one partner could be verified by cross-checking; (2) carefully selecting only directly involved interview partners; (3) outlining the differences between time spans before the interviews (Ingold and Fischer, 2014: 90). While survey partners were also carefully selected and the time span of interest was clearly indicated, I was unable to obtain data on all 128 organizations and to validate their answers by checking their partners' answers.
} 
Table 1

Coefficients for the ergm 2015 and tergm 2011 - 2015.

Source: Own Data.

\begin{tabular}{|c|c|c|}
\hline & Ergm 2015 & Tergm 2011-2015 \\
\hline edges & $\begin{array}{l}-8.32 * * * \\
(0.06)\end{array}$ & $\begin{array}{l}-26.37 * \\
{[-35.18 ;-16.96]}\end{array}$ \\
\hline Internationalization & $\begin{array}{l}0.09 * * * \\
(0.01)\end{array}$ & $\begin{array}{l}0.37 * \\
{[0.26 ; 0.52]}\end{array}$ \\
\hline Profit-Orientation & $\begin{array}{l}-0.03 \\
(0.02)\end{array}$ & $\begin{array}{l}0.08 \\
{[-0.12 ; 0.34]}\end{array}$ \\
\hline Shared Profit-Orientation & $\begin{array}{l}0.01 \\
(0.01)\end{array}$ & $\begin{array}{l}-0.11 \\
{[-0.30 ; 0.14]}\end{array}$ \\
\hline $\begin{array}{l}\text { Prestige (Number of } \\
\quad \text { Commmitees) }\end{array}$ & $(0.02)$ & $\begin{array}{l}0.20 * \\
{[0.07 ; 0.77]}\end{array}$ \\
\hline $\begin{array}{l}\text { Difference in Prestige (Number } \\
\text { of Commmitees) }\end{array}$ & $\begin{array}{l}-0.17^{* * *} \\
(0.01)\end{array}$ & $\begin{array}{l}-0.06 \\
{[-0.63 ; 0.09]}\end{array}$ \\
\hline Size (Number of Employees) & $\begin{array}{l}0.08 * * * \\
(0.01)\end{array}$ & $\begin{array}{l}0.15 * \\
{[0.03 ; 0.19]}\end{array}$ \\
\hline $\begin{array}{l}\text { Difference in Size (Number of } \\
\text { Employees) }\end{array}$ & $\begin{array}{l}-0.02 * \\
(0.01)\end{array}$ & $\begin{array}{l}-0.01 \\
{[-0.27 ; 0.13]}\end{array}$ \\
\hline Political Contacts & $\begin{array}{l}0.03 * * \\
(0.01)\end{array}$ & $\begin{array}{l}0.04 * \\
{[0.02 ; 0.07]}\end{array}$ \\
\hline Shared Genre (Shared Art Type) & $\begin{array}{l}0.02 \\
(0.01)\end{array}$ & $\begin{array}{l}0.01 * \\
{[0.00 ; 0.03]}\end{array}$ \\
\hline $\begin{array}{l}\text { Director's Prior Experience in the } \\
\text { Art Scene }\end{array}$ & $\begin{array}{l}0.19 * * * \\
(0.01)\end{array}$ & $\begin{array}{l}0.25 * \\
{[0.06 ; 0.48]}\end{array}$ \\
\hline $\begin{array}{l}\text { Location (Compared location } \\
\text { "center") }\end{array}$ & $(0.01)$ & $\begin{array}{l}0.17 * \\
{[0.06 ; 0.43]}\end{array}$ \\
\hline Shared Location & $\begin{array}{l}0.06 * * * \\
(0.00)\end{array}$ & $\begin{array}{l}-0.01 \\
{[-0.22 ; 0.26]}\end{array}$ \\
\hline $\begin{array}{l}\text { Category (Compared to type } \\
\text { "foundation") }\end{array}$ & $\begin{array}{l}0.05 * * * \\
(0.01)\end{array}$ & $\begin{array}{l}0.04 \\
{[-0.28 ; 0.26]}\end{array}$ \\
\hline Shared Categories & $\begin{array}{l}0.36 * * * \\
(0.00)\end{array}$ & $\begin{array}{l}0.16 \\
{[-0.04 ; 0.48]}\end{array}$ \\
\hline Age & $\begin{array}{l}0.00 * * * \\
(0.00)\end{array}$ & $\begin{array}{l}0.01 * \\
{[0.00 ; 0.01]}\end{array}$ \\
\hline mutual & $\begin{array}{l}1.43 * * * \\
(0.00)\end{array}$ & $\begin{array}{l}1.33 * \\
{[0.82 ; 1.65]}\end{array}$ \\
\hline gwesp.fixed.1.2 & $\begin{array}{l}0.70 * * * \\
(0.02)\end{array}$ & $\begin{array}{l}0.47 * \\
{[0.42 ; 0.55]}\end{array}$ \\
\hline gwdsp.fixed.1.2 & $\begin{array}{l}-0.03 * * \\
(0.01)\end{array}$ & $\begin{array}{l}-0.08 * \\
{[-0.16 ;-0.04]}\end{array}$ \\
\hline gwidegree & $\begin{array}{l}-0.94 * * * \\
(0.00)\end{array}$ & $\begin{array}{l}-0.82 * \\
{[-1.02 ;-0.51]}\end{array}$ \\
\hline gwodegree & $\begin{array}{l}-1.45 * * * \\
(0.00)\end{array}$ & $\begin{array}{l}-1.54 * \\
{[-1.83 ;-1.21]}\end{array}$ \\
\hline cycle4 & $\begin{array}{l}-0.05 * * * \\
(0.01)\end{array}$ & $\begin{array}{l}-0.01 \\
{[-0.06 ; 0.02]}\end{array}$ \\
\hline isolates & $\begin{array}{l}-0.92 * * * \\
(0.01)\end{array}$ & $\begin{array}{l}-0.08 \\
{[-0.93 ; 0.64]}\end{array}$ \\
\hline edgecov.memory[[i]] & & $\begin{array}{l}2.42 * \\
{[2.31 ; 2.72]}\end{array}$ \\
\hline AIC & 3865.19 & \\
\hline BIC & 4027.44 & \\
\hline Log Likelihood & -1909.59 & \\
\hline & $\begin{array}{l}* * * \mathrm{p}<0.001, * * \mathrm{p} \\
<0.01, * \mathrm{p}<0.05\end{array}$ & $\begin{array}{l}\text { Num. obs. } 23654 \\
* 0 \text { outside the } \\
\text { confidence interval }\end{array}$ \\
\hline
\end{tabular}

Location: The data obtained from Arteria indicated neighborhoods. In 2015, counts for the three different areas in Bogotá were as follows: 19 central organizations (Centro) were coded as $2 ; 44$ organizations in Chapinero as 1; and 30 organizations in the North as 3 . The model compares whether central organizations are more likely to engage in cooperation than organizations located in Chapinero or in the North. The information is thus included as a categorical attribute on the nodes (nodefactor.Location with base $=2$ ). Moreover, I calculated an adjacency matrix, indicating whether any two organizations shared the same location. This was included as an attribute on the edges (edgecovariate). The latter term indicates whether art organizations are more likely to cooperate if they are located in the same area (see supplementary materials for a map on the locations of the art organizations).

Contact to political authorities relevant for cultural policy: The questionnaire asked respondents to select which political institutions they maintained working relationships with: Ministerio de Cultura, Ministerio de Relaciones Exteriores, Pro Colombia, Cámara de Comercio de Bogotá, Idartes, Alcaldía de Bogotá, Fontur, or any other entity. Alternatively, they could select the option 'Not in contact with any political authority'. Allowing respondents to name an additional entity resulted in a variable with values from 0 to 8 . After selecting their contacts, the organizations were asked in which year they had been in contact with the mentioned political institutions. The reported data in 2015 included values from 1 (minimum) to 7 (maximum). The mean was 1.67, while the median was at 1 . The standard deviation was at 1.66.

Internationalization of the art organization: The survey asked organizations whether they had exchanged artists or exhibitions with other organizations beyond Latin America. The variable international was assigned the value 1 if organizations had engaged in at least one such exchange, and 0 if they had not done so in any given year. In 2015, 49 organizations reported no exchanges, while 44 organizations reported at least one.

Age: Recently established organizations may not yet possess a very wide network of relations (Kale et al., 2000: 225). The respondents were asked to provide the year in which their organization was founded. Possible answers ranged from 1900 to 2015. The oldest organizations were founded in 1900, the most recent in 2015. The mean year of foundation was 1997, while the median year was 2009. Standard deviation was 26.60 .

Prior work experience of organization's director in Bogotá's art scene: The survey asked respondents whether their director had worked with an art organization in Bogotá prior to his or her engagement. The variable records 0 for organizations whose directors had no prior experience, and 1 for directors with prior experience. In 2015, 42 of the 93 respondents had no prior experience, while 51 did.

Profit-orientation: Profit-oriented organizations were coded as 1, notfor-profit ones as 2 . In 2015, there were 37 profit-oriented organizations and 56 not-for-profit ones. For profit-orientation, a nodematch term accounts for the tendency of organizations to cooperate with similar organizations.

Resources: Organizations establish different types of cooperation to gain access to resources otherwise lacking (Mizruchi, 1993: 47; Oliver and Ebers, 1998: 565; Gulati and Gargiulo, 2000: 1; Pfeffer, 1987: 26; Borgatti and Foster, 2003: 997; Grandori and Soda, 1995: 185). Organizational size, measured as the number of employees, was used as an indicator for resources. Respondents indicated how many employees worked in their organizations $1-5,6-10,11-20$, and more than 20 for each year from 2011 to 2015 . The variable was recoded with values ranging from 1 to 4 , representing the different sizes. In 2015, the observed minimum was 1 , the maximum 4 . There were 54 small organizations, 20 intermediate ones, 7 large ones, and 12 very large ones. The models also include a term analyzing whether differences in the size increase or decrease the likelihood of cooperation (absolute difference term on the number of employees).

Type of organization: The list of organizations provided by Arteria distinguishes four types of organizations: museums, galleries, foundations, and independent art spaces. In 2015, there were 20 independent art spaces (category 1), 26 foundations (category 2), 37 galleries (category 3 ), and 10 museums (category 4). The variable category included a categorical covariate term on the nodes (nodefactor term), for which the basis of 2 was defined. This served to compare whether foundations are more likely to cooperate than the other three types of organizations. Further, an adjacency matrix, included as an edgecovariate term, indicates whether any two organizations from the same category are more likely to cooperate. 
Dyad-wise shared partners

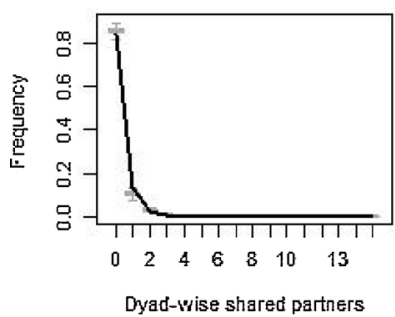

Indegree

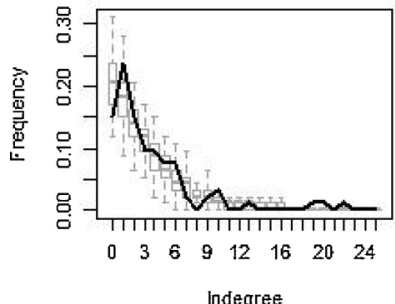

Modularity (walktrap)

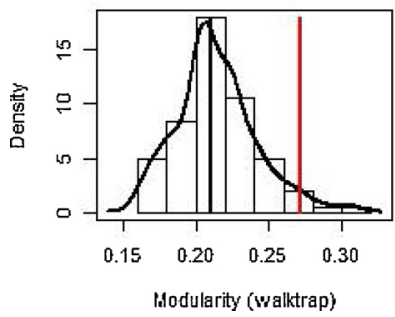

Edge-wise shared partners

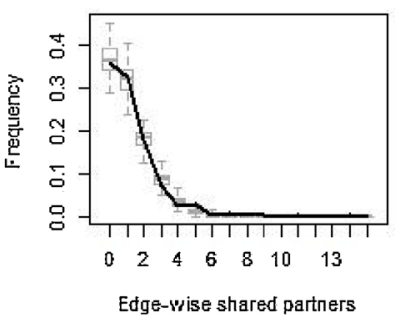

Geodesic distances

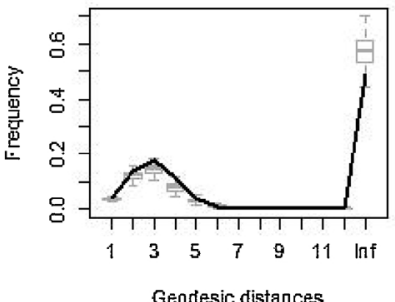

Degree
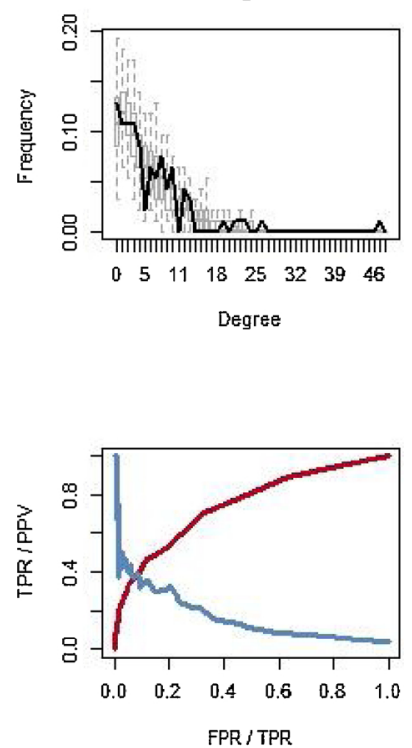

Fig. 5. Goodness of Fit Plot for the Network 'Joint Organization of an Event' in 2015. Source: Own Data.

Artistic orientation: Organizations specified their particular type of exhibited artworks by choosing from a list of labels. The different genres were extracted from the pre-survey interviews. Organizations were asked to select the corresponding number of genres from a total of 33. Responses were used to construct an adjacency matrix with values from 0 to 33, specifying the number of shared art types for any two organizations. The variable was included as an edge covariate. In 2015, the lowest number of shared genres of artworks among any two organizations was 0 , the highest 29 . The mean was at 4.91 , the median at 4 . The standard deviation was 4.10 .

\section{Estimation: exponential random graph models}

The network was modeled with exponential random graph models. The interpretation of the ergm corresponds to the interpretation of a logistic regression model of the formation of ties, where some of the independent variables represent statistics on structures incorporating other ties in the network. The probability of observing a particular network is given by the following probability density function, where $\mathrm{N}$ specifies the network, and $\theta$ the coefficients to be modeled:

$P(N, \theta)=\frac{\exp \left\{\theta^{T} h(N)\right\}}{\sum_{N^{*} \in N} \exp \left\{\theta^{T} h\left(N^{*}\right)\right\}}$

$h(N)$ are the network statistics requiring specification. They may include endogenous (i.e. edgewise shared partners), as well as exogenous characteristics (i.e. number of employees). $\theta$ is a vector of the estimated coefficients. The symbol $\mathrm{T}$ indicates that a transpose is taken. The numerator, $\exp \left\{\theta^{T} h(N)\right\}$, is the exponentiated sum of the weighted statistics of the observed network (i.e., the one to be modeled). The denominator $\sum_{N^{*} \in N} \exp \left\{\theta^{T} h\left(N^{*}\right)\right\}$ sums these exponentiated sums of weighted statistics. Thus, the whole expression is the probability of observing this particular network depending on the statistics included and given all the other possible networks that might have been observed, conditioning on covariates. This expression is problematic for estimation because the set of all possible permutations of the network with the same number of nodes is very large, even for small networks.

To determine parameter size, artificial networks were first sampled. Simulating new networks given the selected parameters is referred to as network sampling. Network sampling can be performed based on different sampling procedures (i.e., Markov Chain Monte Carlo (MCMC) sampling procedure based on Metropolis-Hastings algorithm). Next, the sampled networks, which are as close as possible to that empirically observed, were identified. For any sampled network, closeness to the observed network was therefore evaluated by comparing its sampling statistics to those of the observed networks. The difference between the observed network and the sampled ones was minimized by sampling over and over again and by accepting the parameter configuration yielding the most accurate networks (i.e. maximum likelihood (MLE)). This procedure is called MCMC-MLE and is used to estimate ergms. The combined network for 2015 was modeled with an ergm, including the exogenous and endogenous terms discussed in the previous section. The ergm models presented here are based on MCMC network sampling and on MLE estimation.

The networks between 2011 and 2015 were estimated with the same model terms, but with a temporal ergm (tergm). A tergm allows including temporal effects in the $\mathrm{h}(\mathrm{N})$ term, so as to specify different types of time dependencies between the networks (Leifeld et al., 2018). Among temporal dependencies that can be modeled, a special role is assumed by so-called memory terms. These capture intertemporal 
Dyad-wise shared partners

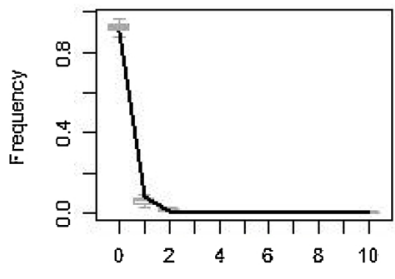

Dyad-wise shared partners

Indegree

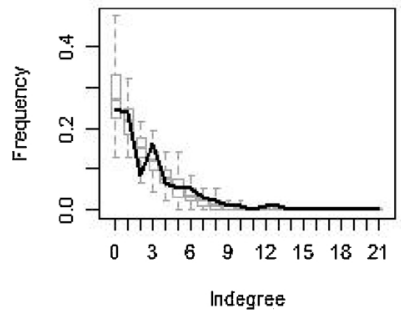

Modularity (walktrap)

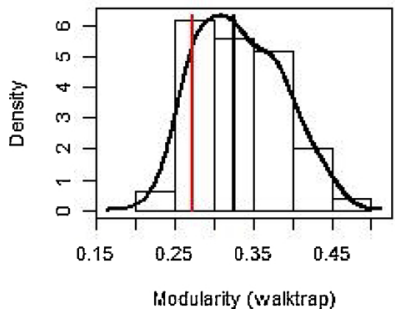

Edge-wise shared partners

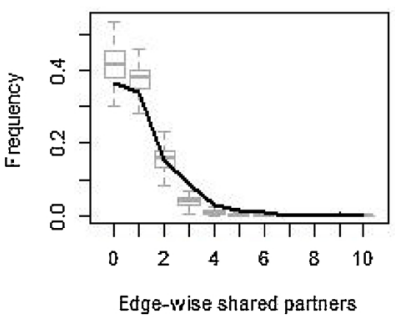

Geodesic distances

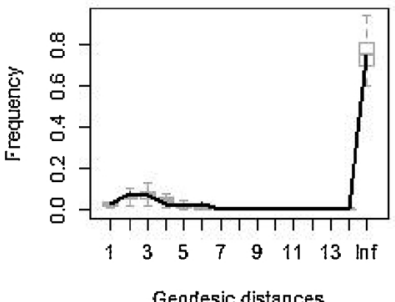

Degree
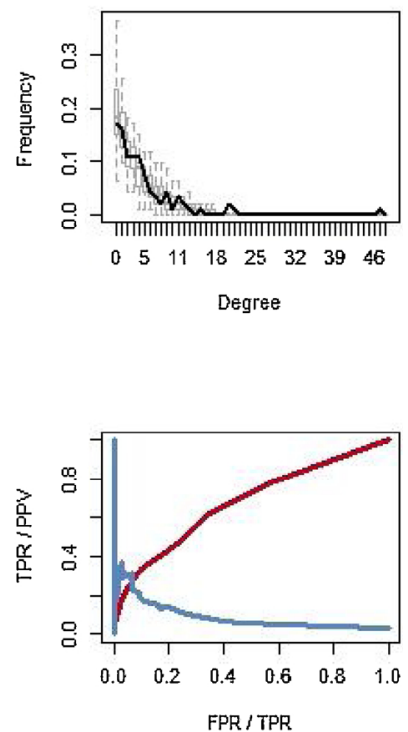

Fig. 6. Goodness of Fit Plot for the Network 'Participation in a Joint Event' in 2015. Source: Own Data.

dependencies without capturing additional network structure. They capture for instance a tendency of existing and non-existing ties to persist over time. As discussed, such a memory term of type "stability" was applied in the model for the the five networks for 2011 to 2015. Estimation is more complicated with these additional possibilities of temporal dependencies, because MCMC-MLE becomes computationally too demanding. Therefore the estimation of tergms is based on MCMC network sampling and on maximum pseudo likelihood estimation. In this estimation procedure, confidence intervals are biased downwards. This is corrected for by applying a bootstrap method for constructing confidence intervals (Desmarais and Cranmer, 2012: 1868).

Figs. 3 and 4 show how the actually observed networks (black line) compare to the networks drawn from the ergm and tergm models (confidence intervals) across different network statistics.

The plots indicate an adequate fit across all parameters, as the black line representing the observed network lies within the confidence interval derived from the generated networks from the models for all network parameters. ${ }^{\mathrm{vi}}$ The good fit is owed to a careful selection of parameters, which reflects the researchers' knowledge on the art scene gained through the 36 interviews conducted before the survey. Moreover, comparing the precision recall curves (in each figure, the second graph from above, the first on the right) shows that the tergm correctly predicts significantly more ties and non-ties compared to the ergm on the network in 2015 (see supplementary materials for MCMC

\footnotetext{
${ }^{\text {vi }}$ One concern is that the impact of the independent variables should be allowed to differ across years. Comparing model coefficients for different years indicates that specific time interaction effects need not be included with any of the variables as the coefficients are reasonably close to one another (see supplementary material).
}

diagnostics plots). However, as the model takes into account previous realizations of the same network to predict the ties in the next network, this predictive quality is relativized. Depending on the duration of the time steps (i.e., if separate networks were observed every day), the changes to be predicted are not very large.

\section{Empirical results: prestige matters}

Table 1 below shows the coefficients for the exogenous and endogenous variables for both, the ergm for the combined 2015 network and the tergm.

The following discussion concentrates on the role of prestige in overcoming social dilemma. Prestige was found to be positive and significant both in the tergm and in the ergm for 2015. Highly recognized organizations were thus more likely to cooperate than less recognized ones. Further, in the network for 2015 cooperation did not occur across different levels of prestige. The absolute difference terms on prestige were negative and significant in the ergm for 2015 but failed to be significant in the tergm for all four years. The model for 2015 thus reveals an interesting pattern: highly recognized organizations cooperate predominantly among themselves. The same applies to less recognized ones, albeit at lower levels of cooperation.

In a next step, all four forms of cooperation are compared. A similar model is applied to the different networks representing the different forms of cooperation in 2015. The exogenous terms are the same as in the previous model. Endogenous terms vary from network to network so as to achieve a better fit. It is not unreasonable to assume that different forms of cooperation follow different network dynamics. Apart from a GW-esp and 3- and 4-cycles, other network dynamics are included in different combinations: mutuality of ties, GW-idegree, GW- 

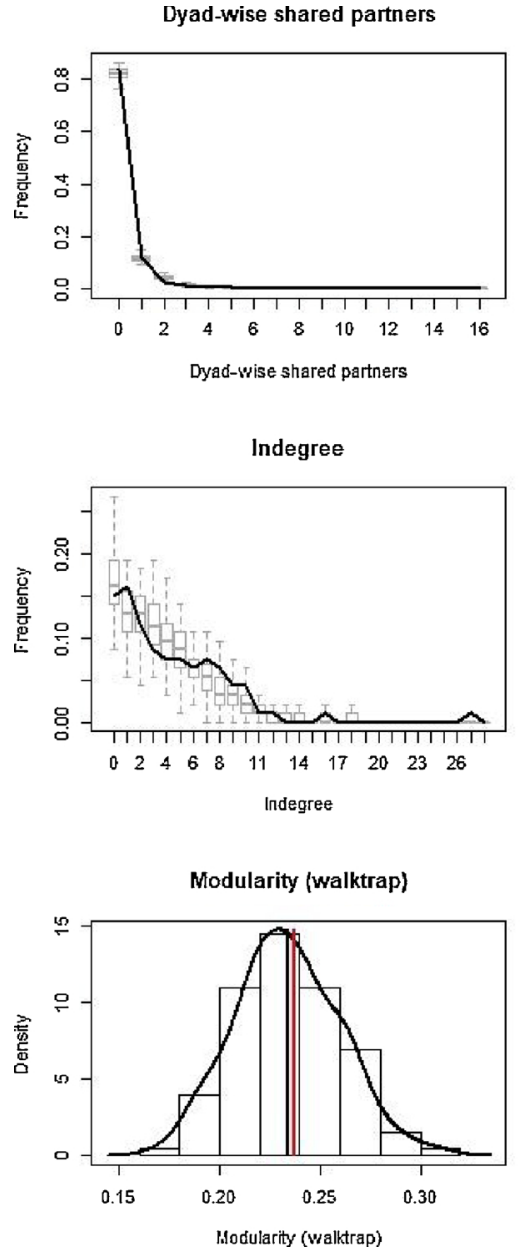
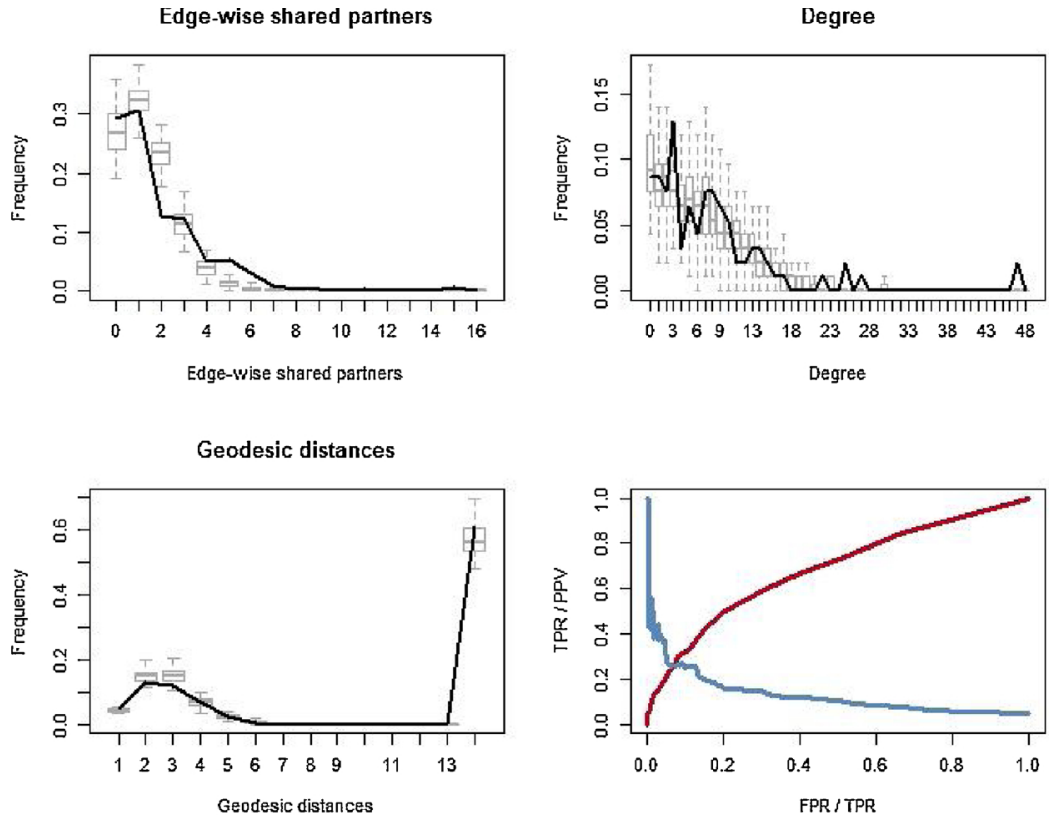

Fig. 7. Goodness of Fit Plot for the Network 'Circulating Visitors' in 2015. Source: Own Data.

odegree, and isolates. Not included in any of the models was the term dyad-wise shared partners.

While model fit is satisfactory for all networks, it is slightly less so for the network regarding the circulation of content. The circulation of exhibitions might not be so easy to model because this form of cooperation is infrequent in Bogotá's art circuit. Exhibitions tend to be circulated across cities, or internationally, but not among local art organizations. The Circulation of Content network also exhibits the lowest density of the four networks (0.025), compared to 0.047 for Shared Visitors, 0.038 for Organizing Events, and 0.028 for Participating in the Same Events (Figs. 5-9).

Prestige was significant in the two models run on the combined networks. Zooming-in on the different forms of cooperation reveals that prestige does not play the same role in all forms of cooperation.

Prestige is significant and positive in participating in and organizing events. Highly recognized organizations are thus more likely to cooperate. Moreover, in these two forms of cooperation organizations do not connect across different levels of prestige (negative significant absdiff term). This corresponds to the results obtained from modeling the combined networks (2015 and the tergm). In contrast, prestige is insignificant in circulating visitors and content. The absolute difference term is either insignificant (circulation of visitors) or positive (circulation of content). The cooperation taking place in these forms reveals a different pattern: the level of prestige of an organization does not affect the likelihood of cooperation. Moreover, there seems to be no effect of organizations' difference regarding prestige on their likelihood of cooperation.

This suggests that two different dynamics are involved, depending on the forms of cooperation. In some forms of cooperation, more prestigious organizations cooperate more frequently than less prestigious ones. Here, cooperation does not occur across different levels of recognition (significant negative absdiff term). These dynamics concern the two more visible forms of cooperation (i.e., organizing joint events and participating in the same event). In the two other forms of cooperation, prestige does not play a role in the likelihood of organizations' cooperation. Here, difference in prestige does not affect the likelihood of cooperation, or organizations are even more likely to cooperate across different, rather than similar levels of prestige. This suggests that less prestigious organizations cooperate with highly recognized organizations in order to gain prestige. These forms of cooperation are not as visible (circulation of visitors and exchanging artists or exhibitions). While prestige affects cooperation in social dilemma, the effect of prestige depends on the form of cooperation.

\section{Conclusion}

This paper has found that prestige matters in social dilemmas. Comparing this finding to the initial theoretical discussion (where motivational solutions to social dilemmas included norms of fairness) reveals that prestige does not presuppose a pro-social orientation 
Dyad-wise shared partners
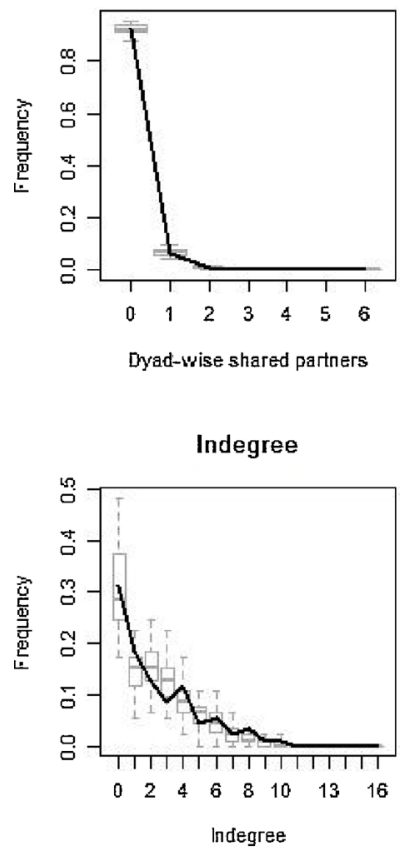

Modularity (walktrap)

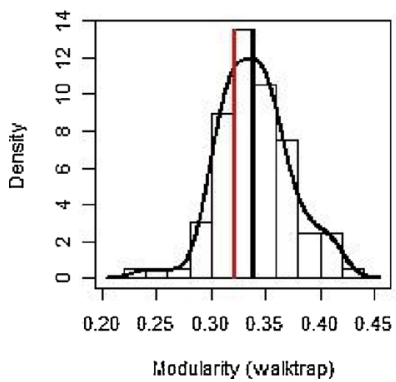

Edge-wise shared partners

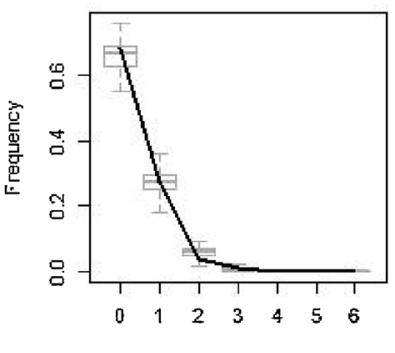

Edge-wise shared partners

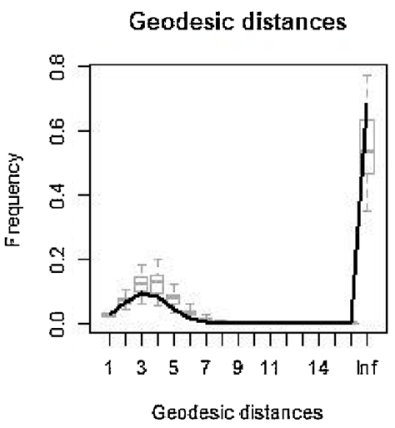

Degree
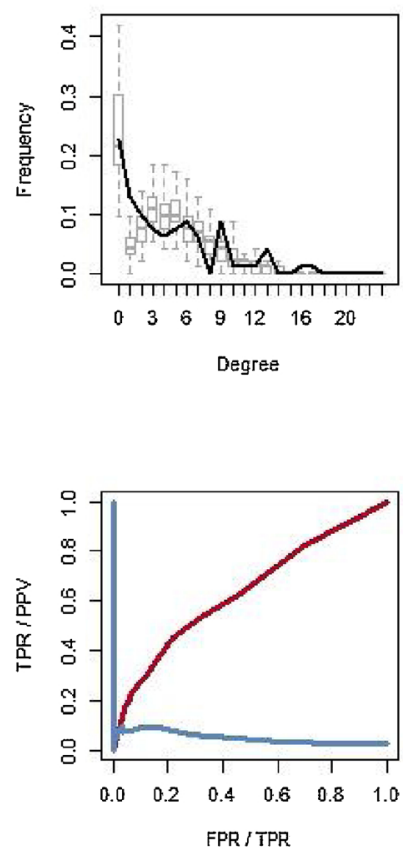

Fig. 8. Goodness of Fit Plot for the Network 'Circulating Content' in 2015. Source: Own Data.

among organizations. Similar to strategic solutions, in which organizations refrain from cheating because they are avoided as counterparts otherwise, building prestige aligns individual and collective rationality. Rational actors, individuals and organizations alike, desire to be recognized by others. Such recognition depends on others. Crucially, in fact, as prestige is constituted in social relations. Prestige therefore builds an interesting bridge between self-interest and orientation towards others.

The effect of prestige depends on the form of cooperation. In more visible forms of cooperation, prestigious organizations are more likely to cooperate, and to cooperate mostly among themselves. Prestige in this first dynamic stimulates cooperation among a particular group of organizations, but limits cooperation across the group boundary. In less visible forms of cooperation, prestigious and less recognized organizations are equally likely to cooperate, and cooperation is more likely to take place across different levels of recognition. In this second dynamic, less recognized organizations may gain prestige by associating themselves with highly recognized organizations.

Prestige not having the same effect in all forms of cooperation indicates that it is context-specific, at least to some extent. Thus, do these findings travel to other contexts? On the one hand, organizations may associate in different forms, though not necessarily through cooperating in social dilemmas, in order to build prestige. On the other, prestige may not matter in any social dilemma. Prestige is highly relevant in cultural industries, but may be less important in others. However, insofar as recognition of certain qualities is an important motive for organizations as well as in human interaction, it is likely to play a role in other contexts as well. Depending on the visibility of the form of cooperation, the two different dynamics identified might also apply to other contexts. As such, they present an interesting avenue for future research.

Last but not least, the network analytic approach applied here has allowed assessing the probability of cooperation between dyads, while controlling for the interactions in time and the overall structure of the network. Thus, network analysis might provide a very interesting approach to analyzing social dilemmas. It is used to model interactions more generally, where payoff structures may or may not represent social dilemmas. Payoffs in real-world interactions are rarely as clear as in experimental settings. Their analysis requires both accurate characterization and high contextual awareness among researchers. 
Organization of a Joint Event 2015
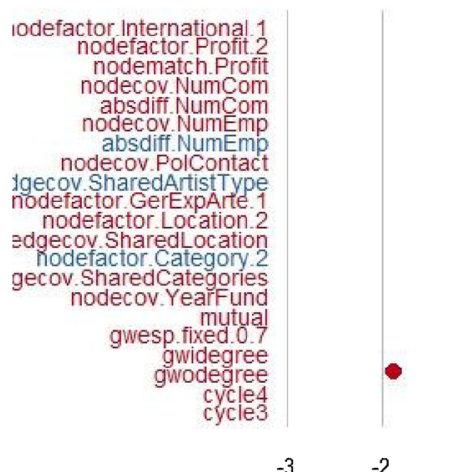

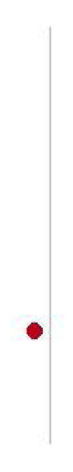

2

Bars denote Cls.

\section{Circulation of Visitors 2015}

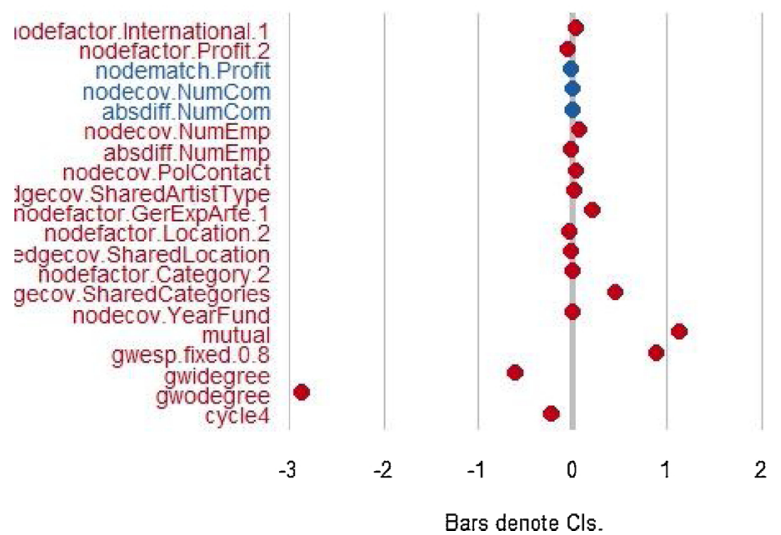

Participation in a Joint Event 2015

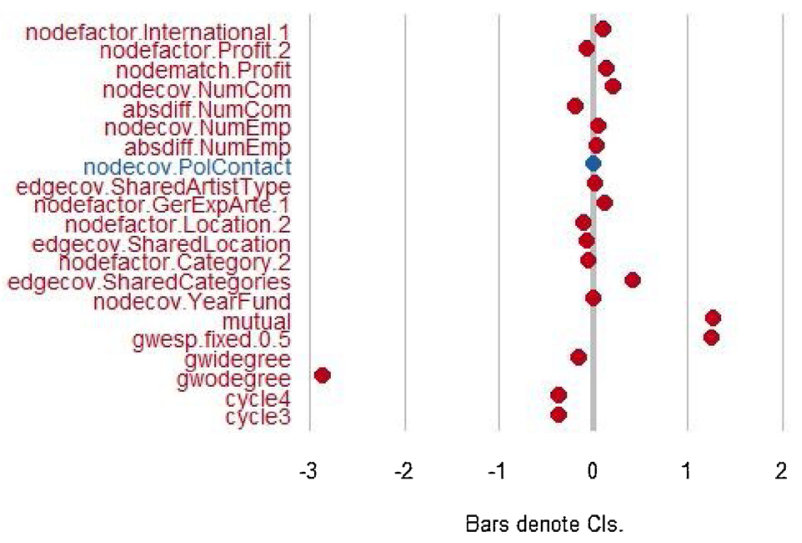

Circulation of Content 2015

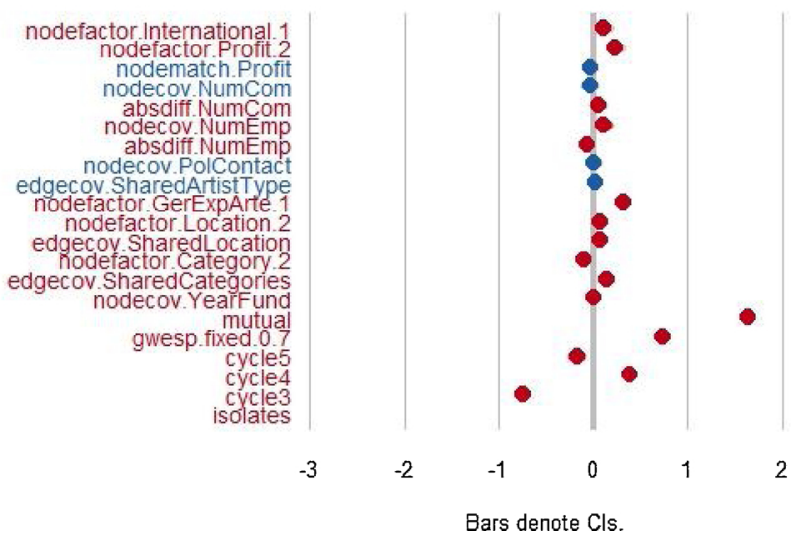

Fig. 9. Significance of Coefficients for the Same Model on All Four Forms of Cooperation for 2015 (in color). For better readability, the coefficients on edges were excluded. The coefficients were as follows: Organization of a joint event (-9.30), Participation in a joint event (-12.26), circulation of visitors (-10.44), circulation of content (-13.13). Source: Own Data.

\section{Declaration of Competing Interest}

The author does not report any competing interests.

\section{Acknowledgement}

I thank the two anonymous reviewers. Their feedback has been extremely helpful. I thank Marianne Jäggi Aerne, Patrick Emmenegger, Klaus Dingwerth and Giuliano Bonoli for their critical comments on earlier versions, and Alexander Calderón who has generously supported me when I encountered technical problems.

\section{Appendix A. Supplementary data}

Supplementary material related to this article can be found, in the online version, at doi:https://doi.org/10.1016/j.socnet.2019.12.001.

\section{References}

Axelrod, Robert., 1984. The Evolution of Cooperation. Basic Books, New York. Borgatti, S.P., Foster, P.C., 2003. The network paradigm in organizational research: a review and typology. J. Manage. 29, 991-1013.

Bowles, S., Choi, J.-K., Hopfensitz, A., 2003. The co-evolution of individual behaviors and social institutions. J. Theor. Biol. 223, 135-147.

Braden, L.E., 2009. From the Armory to academia: careers and reputations of early modern artist in the United States. Poetics 37, 439-455.

Culpepper, P., 2000. Can the state create cooperation?: problems of reforming the labor supply in France. J. Public Policy 20, 223-245.

Desmarais, B.A., Cranmer, S.J., 2012. Statistical mechanics of networks: estimation and uncertainty. Physica A A 391, 1865-1876.

van Dijk, Nel, 1999. Neither the top nor the literary fringe: The careers and reputations of middle group authors. Poetics 26, 405-421.

Dijkstra, J., van Assen, M.A.L.M., 2013. Network public goods with asymmetric information about cooperation preferences and network degree. Soc. Networks 35, 2573-2582.

Elster, J., 1989. The Cement of Society. A Study of Social Order. Cambridge University Press, Cambridge.

Fehr, E., Fischbacher, U., 2004. Social Norms and human cooperation. Trends Cogn. Sci. (Regul. Ed.) 8, 185-190.

Fehr, E., Schmidt, K.M., 1999. A theory of fairness, competition and cooperation. Q. J. Econ. 817-868.

Freeland, R.E., Hoey, J., 2018. The structure of deference: modeling occupational status using affect control theory. Am. Sociol. Rev. 83, 243-377.

Giuffre, K., 1999. 'Sandpiles of opportunity: success in the art world. Soc. Forces 77, 815-832.

Goffman, E., 1956. The nature of deference and demeanor. Am. Anthropol. 58, 473-502. Grandori, A., Soda, G., 1995. Inter-firm networks: antecedents, mechanisms and forms. Organ. Stud. 16, 183-214.

Granovetter, M.S., 1985. Economic action and social structure: the problem of embeddedness. Am. J. Sociol. 91, 415-510.

Gulati, R., Gargiulo, M., 2000. Where Do interorganizational networks come from? In: Weesie, J., Raub, W. (Eds.), The Management of Durable Relations: Theoretical Models and Empirical Studies of Households and Organizations. ThelaThesis, Amsterdam.

Heckathorn, D.D., 1996. The dynamics and dilemmas of collective action. Am. Sociol. Rev. 61, 250-277.

Ingold, K., Fischer, M., 2014. Drivers of collaboration to mitigate climate change: an illustration of Swiss climate policy over 15 years. Glob. Environ. Chang. Part A 24, 88-98.

Irwin, K., Simpson, B., 2013. Do descriptive norms solve social dilemmas? Conformity contributions in collective action groups. Soc. Forces 91, 1057-1084.

Kale, P., Singh, H., Perlmutter, H., 2000. Learning and protection of proprietary assets in strategic alliances: building relational capital. Strateg. Manage. J. 21, 217-237.

Kollock, P., 1998. The anatomy of cooperation. Annu. Rev. Sociol. 24, 183-214. 
Lazega, E., Pattison, P., 1999. Multiplexity, generalized exchange and cooperation in organizations: a case study. Soc. Networks 21, 67-90.

Leifeld, P., Cranmer, S.J., Desmarais, B.A., 2018. Temporal exponential random graph models with btergm: estimation and bootstrap confidence intervals. J. Stat. Softw. 83, $1-36$.

Macy, M.W., Skvoretz, J., 1998. The evolution of trust and cooperation between strangers: a computational model. Am. Sociol. Rev. 63, 638-660.

Marwell, G., Oliver, P.A., Prahl, R., 1988. Social networks and collective action: a theory of the critical mass. Am. J. Sociol. 94, 502-534.

Mizruchi, M.S., 1993. Networks of interorganizational relations. Sociol. Methods Res. 22, 46-70.

de Nooy, Wouter, 2002. 'The dynamics of artistic prestige. Poetics 30, 147-167.

Oliver, A.L., Ebers, M., 1998. Networking network studies: an analysis of conceptual configurations in the study of inter-organizational relationships. Organ. Stud. 19, 549-583.

Olson, Mancur., 1965. The Logic of Collective Action. Public Goods and the Theory of Groups. Harvard University Press, Cambridge.

Ostrom, E., 2000. Collective action and the evolution of social norms. J. Econ. Perspect. 14, 137-158.

Peñaranda, Nelly, Guerrero, Diego, Sánchez, Santiago, Bray, Caroline Peña, Ferregán, Gustavo, 2015. Directorio Bogotá Arte Circuito 2015-2016. Fundación Arteria,
Bogotá.

Pfeffer, Jeffrey., 1987. A resource dependence perspective on intercorporate relations. In: Mizruchi, Mark S., Schwartz, Michael (Eds.), Intercorporate Relations - The Structural Analysis of Business. Cambridge University Press, Cambridge.

Raub, W., Buskens, V., Frey, V., 2013. The rationality of social structure: cooperation in social dilemmas through investments in and returns on social capital. Soc. Networks 35, 720-732.

Raub, W., Weesie, J., 1990. Reputation and efficiency in social interactions: an exmaple of network effects. Am. J. Sociol. 96, 626-654.

Sell, J., Wilson, R.K., 1999. The maintenance of cooperation: expectations of future interaction and the trigger of group punishment. Soc. Forces 77, 1551-1570.

Simpson, B., 2003. Sex, fear, and greed: a social dilemma analysis of gender and cooperation. Soc. Forces 82, 35-52.

Starkey, K., Barnatt, C., Tempest, S., 2000. Beyond networks and hierarchies: latent organizations in the U.K. Television industry. Organ. Sci. 11, 299-305.

Tomochi, M., 2004. Defectors' niches: prisoner's dilemma game on disordered networks Soc. Networks 26, 309-321.

Verboord, Marc., 2003. Classification of authors by literary prestige. Poetics 31, 259-281. Winter, F., Rauhut, H., Helbing, D., 2012. How norms can generate conflict: an experiment on the failure of cooperative micro-motives on the macro-level. Soc. Forces 90 919-948. 